\title{
DESEMPENHO DE HÍBRIDOS DE CAJUEIRO-ANÃO-PRECOCE NO LITORAL DO ESTADO DO CEARÁ ${ }^{1}$
}

\author{
EGNESIO HOLANDA VALE ${ }^{2}$, MARAISA CRESTANI HAWERROTH ${ }^{3}$, \\ JOSÉ JAIME VASCONCELOS CAVALCANTI ${ }^{4}$, FRANCISCO DAS CHAGAS VIDAL NETO 5 , \\ DHEYNE SILVA MELO
}

RESUMO - A seleção de genótipos de cajueiro em progênies segregantes obtidas via hibridações artificiais representa em uma oportunidade de associação de genes favoráveis, herdados de genitores conhecidos. Adicionalmente, conhecer a dinâmica dos principais caracteres de interesse pode auxiliar na definição de estratégias eficientes para a obtenção de ganhos genéticos. Logo, o objetivo do trabalho foi avaliar o desempenho produtivo e caracteres morfológicos de progênies de irmãos completos de cajueiro, conduzidas no município de Pacajus-CE, ao longo de três safras de cultivo, e estimar as correlações entre os caracteres de interesse. Nas safras de 2010, 2011 e 2012, foram avaliadas sete progênies de cajueiro em relação a caracteres morfológicos e produtivos. Os cruzamentos CCP 76 x BRS 226, CCP 76 x Embrapa 51 e BRS 226 x Embrapa 51 mostraram-se promissores na geração de genótipos superiores para caracteres de interesse agronômico. $\mathrm{O}$ porte da planta apresentou associações positivas com a produtividade de castanhas, e o número de castanhas por planta evidenciou forte correlação com a produtividade. Portanto, ressalta-se a necessidade de realizar a seleção buscando o equilíbrio em relação ao desempenho nos caracteres morfológicos e produtivos, visando à obtenção de genótipos que associem a elevada produtividade de castanhas e adequado porte de planta.

Termos para indexação: Anacardium occidentale L., progênies, desempenho agronômico.

\section{PERFORMANCE OF HYBRID OF PRECOCIOUS DWARF CASHEW ON THE COAST OF THE STATE OF CEARÁ}

\begin{abstract}
The selection of cashew genotypes in segregating progenies obtained via artificial hybridization consists of a chance to associate favorable genes inherited from known parents. Additionally, knowing the dynamics of the main characters of interest can help define effective strategies to obtain genetic gains. So, the objective of this study was to evaluate the performance of cashew full-sib progenies in relation to production and morphological characters, cultivated in the municipality of Pacajus-CE in three growing seasons, and to estimate the correlations among traits of interest. In the seasons of 2010, 2011 and 2012 were evaluated seven progenies of cashew in relation to morphological and productive characters. The crosses CCP 76 x BRS 226, CCP 76 x Embrapa 51 and BRS 226 x Embrapa 51 shown to be promising in generating superior genotypes for agronomic interest characters. The size of the plant showed positive associations with productivity of nuts, and the number of nuts per plant showed strong correlation with yield. So, it is important to emphasize the necessity to perform the selection seeking balance in relation to the performance on morphological and productive characters in order to obtain genotypes that combine high productivity of nuts and appropriate size of plant.
\end{abstract}

Index terms: Anacardium occidentale L., progeny, agronomic performance.

\footnotetext{
'(Trabalho 403-13). Recebido em: 16-09-2013. Aceito para pubilcação em: 09-10-2014.

${ }^{2}$ Eng. Agr., Aluno de Mestrado em Fitotecnia, Universidade Federal do Ceará, Cep 60356-000, Fortaleza-CE, Brasil. E-mail: egnvale@ yahoo.com.br

${ }^{3}$ Eng. Agr., DSc., Bolsista de Desenvolvimento Científico e Tecnológico Regional - DCR CNPq/FUNCAP - sede na Embrapa Agroindústria Tropical. Cep 60511-110, Fortaleza-CE, Brasil. E-mail: maraisacrestani@gmail.com;

${ }^{4}$ Eng. Agr., DSc., Pesquisador, Embrapa Algodão, Cep 58428-095, Campina Grande-PB, Brasil. E-mail: jaime.cavalcanti@embrapa.br. ${ }^{5}$ Eng. Agr., DSc., Pesquisador, Embrapa Agroindústria Tropical, Cep 60511-110, Fortaleza-CE, Brasil. E-mails: vidal.neto@embrapa.br; dheyne.melo@embrapa.br.
} 


\section{INTRODUÇÃO}

O cajueiro (Anacardium occidentale L.) é uma cultura de grande importância para a agricultura de regiões semiáridas, contribuindo para o desenvolvimento socioeconômico de diversas regiões do mundo, basicamente através da exploração comercial da castanha e do pseudofruto do caju (TARSITANO et al., 2010). No que diz respeito à produção de castanha no Brasil, nas últimas décadas, praticamente toda a produção se concentra na região Nordeste, tendo como maiores produtores os Estados do Ceará, Rio Grande do Norte e Piauí, que, juntos, respondem por aproximadamente $93 \%$ da produção nacional de castanha (IBGE, 2012). O Brasil está entre os maiores produtores de castanha de caju no mundo, sendo que, na safra de 2012, foram cultivados e colhidos 756.846 ha, obtendo-se a produção total de $80.630 \mathrm{t}$, com a produtividade média de $106,5 \mathrm{~kg} \mathrm{ha}^{-1}$ (FAOSTAT, 2014). Esses dados contrastam com o cenário produtivo mundial, pois na safra agrícola de 2012, foi verificada produtividade média significativamente superior, igual a $781,5 \mathrm{~kg}$ de castanha por hectare(FAOSTAT, 2014). Esse desempenho ineficiente deve-se ao fato de a cajucultura brasileira ter como característica geral a precária utilização das tecnologias de produção desenvolvidas, resultando em cajueirais constituídos, em sua maioria, por material genético de qualidade inferior, manejados de forma inadequada, culminando na baixa qualidade e produtividades, e, consequentemente, reduzida remuneração pela castanha. Logo, o melhoramento genético assume um papel importante no sentido de disponibilizar ao mercado genótipos superiores que venham a contribuir para a consolidação da cajucultura como atividade rentável e sustentável no Brasil.

A introdução de germoplasma, a seleção clonal e a hibridação artificial caracterizam as técnicas de melhoramento mais comumente adotadas na cultura do cajueiro (CAVALCANTI et al., 2007). O desenvolvimento de clones-elite por meio de hibridações artificiais entre cajueiro-anão-precoce e cajueiro comum, seguida da caracterização e seleção de plantas superiores dentro das progênies, é uma importante estratégia para a ampliação da variabilidade e a obtenção de ganhos genéticos nesta cultura (CAVALCANTI et al., 2000). Até então, a grande maioria dos clones comerciais de cajueiro lançados é produto da seleção fenotípica em populações naturais ou melhoradas (populações de meios-irmãos), com a ausência de controle parental ou conhecimento apenas dos genitores femininos (CAVALCANTI et al., 2010).
A realização de hibridações artificiais dirigidas, adotando o controle concomitante dos genitores masculinos e femininos, ainda tem sido pouco utilizada no melhoramento do cajueiro; contudo, apresenta a vantagem de oportunizar a tentativa de associar em um único genótipo genes favoráveis herdados dos genitores conhecidos, caracterizados em relação aos caracteres de interesse. A adoção de genitores que evidenciem elevado desempenho para os caracteres de interesse agronômico é imprescindível para a formação de um adequado germoplasma-elite a ser explorado pelo programa. Adicionalmente, informações a respeito dos efeitos envolvidos na expressão fenotípica dos caracteres em populações segregantes de cajueiro, cultivadas ao longo de diferentes anos, bem como o entendimento da dinâmica da expressão via estudos de correlação, podem auxiliar na definição de estratégias que venham a otimizar a obtenção de ganhos genéticos com a seleção. Desta forma, o objetivo do trabalho foi avaliar o desempenho produtivo de progênies de irmãos completos de cajueiro, conduzidas no município de Pacajus, Estado do Ceará, ao longo de diferentes safras de cultivo, e estimar as correlações entre diferentes caracteres de interesse agronômico.

\section{MATERIAL E MÉTODOS}

O experimento foi conduzido nas safras agrícolas de 2010, 2011 e 2012, no Campo Experimental de Pacajus, pertencente à Embrapa Agroindústria Tropical, localizado no município de Pacajus, Estado do Ceará (4 ${ }^{\circ} 11^{\prime} 07^{\prime}$ ' sul, $38^{\circ} 30^{\prime}$ $07^{\prime} \mathrm{W}$, e altitude de $70 \mathrm{~m}$ ). O solo característico é do tipo Podzólico Vermelho-Amarelo Tb eutrófico A franco, com textura arenosa média. O clima típico da região é do tipo seco subúmido, e nos anos agrícolas de 2010, 2011 e 2012, foram constatadas as precipitações pluviais d456, 1.388 e 504 mm anuais, respectivamente, e temperaturas médias variando entre 26 e $28^{\circ} \mathrm{C}$.

O experimento foi instalado em 2007, em regime de sequeiro, através da semeadura de sementes provenientes de cruzamentos controlados entre os seguintes genótipos de cajueiro: clone CCP 76 x genótipo de Anacardium microcarpum; clone CCP 76 x clone BRS 226; clone CCP 76 x genótipo HAC 276/1; clone CCP 76 x clone Embrapa 51; clone CCP 76 x clone BRS Bahia 12; clone CCP 76 x genótipo HAC 222/4, e clone BRS 226 x clone Embrapa 51. O delineamento utilizado foi o de blocos casualizados, com quatro repetições, com quatro plantas compondo cada parcela. Adotou-se o espaçamento de oito 
metros entre linhas e seis metros entre plantas, sendo utilizadas como bordadura plantas de cajueiro, adotando-se a densidade de 208,33 plantas por hectare. O preparo do solo da área experimental e as adubações com macronutrientes (NPK), ao longo dos anos de desenvolvimento das plantas, foram realizados conforme recomendações técnicas para a cultura do cajueiro (OLIVEIRA; COSTA, 2005).

As plantas constituintes de cada uma das sete progênies de híbridos $\mathrm{F}_{1}$ de cajueiro foram avaliadas no decorrer das safras agrícolas de 2010, 2011 e 2012, em relação ao desempenho apresentado para os caracteres altura de planta $(\mathrm{m})$, diâmetro de copa (m), produtividade $\left(\mathrm{kg} \mathrm{ha}^{-1}\right)$, número de castanhas por planta (unidade planta-1 ${ }^{-1}$ e massa média de castanha (g). Para a mensuração da altura da planta, utilizou-se régua graduada, sendo efetuada a medição a partir da base da planta até seu ápice. A mensuração do diâmetro da copa foi realizada utilizando fita métrica, considerando as medidas observadas no sentido leste - oeste (E - W) de projeção da copa, considerando a disposição das plantas no campo experimental. As avaliações dos caracteres morfológicos foram realizadas durante o período vegetativo de cada ano de cultivo. A produtividade de castanha foi definida a partir da soma da massa de castanhas colhidas em cada planta constituinte das parcelas no decorrer de todo o ciclo produtivo de cada safra, com a extrapolação dos valores obtidos para a produção por hectare. O número de castanhas por planta foi definido a partir da contagem de todas as castanhas colhidas em cada planta ao longo do ciclo produtivo. A massa média de castanha foi determinada a partir da mensuração da massa de três amostras compostas por 20 castanhas coletadas de cada planta, com posterior obtenção da média aritmética.

Os resultados obtidos foram submetidos à análise de variância, e as variáveis que revelaram significância pelo teste $\mathrm{F}$, a $5 \%$ de probabilidade, tiveram as médias comparadas pelo teste de Tukey, a 5\% de significância. Posteriormente, foram estimados os coeficientes de correlação fenotípica $\left(r_{\mathrm{P}}\right)$, genotípica $\left(\mathrm{r}_{\mathrm{G}}\right)$ e de ambiente $\left(\mathrm{r}_{\mathrm{E}}\right)$. Os testes estatísticos foram realizados com auxílio do Programa Genes, versão 2009.7.0.

\section{RESULTADOS E DISCUSSÃO}

Os fatores progênie e ano de cultivo foram significativos para os caracteres avaliados, exceto para a massa média da castanha, que não revelou significância para o fator ano de cultivo (Tabela 1). No entanto, não foi identificada interação significativa entre os fatores de tratamento progênie e ano de cultivo, sendo possível afirmar que as progênies avaliadas apresentaram desempenhos distintos para os diferentes caracteres avaliados, em decorrência da variabilidade genética entre as mesmas, e que o comportamento foi variável ao longo dos anos de cultivo testados. Ao mesmo tempo, a ausência de significância verificada para o caráter massa média da castanha em relação ao ano de cultivo, possivelmente, é um indicativo de que este caráter é fortemente determinado pela constituição genética dos indivíduos avaliados, sofrendo menor interferência dos fatores ambientais.

Ao longo dos anos de cultivo de 2010, 2011 e 2012, foi constado um incremento constante no desempenho médio dos híbridos para os caracteres altura de planta, diâmetro de copa, número de castanhas por planta e produtividade de castanha, conforme observado na Figura 1. É possível verificar que o aumento no número de castanhas por planta ao longo das safras foi acompanhado pelo aumento da produtividade; contudo, não foi verificada alteração significativa na massa média da castanha. Logo, esse comportamento pode ser associado ao fato de as plantas em avaliação apresentarem-se em estádio de desenvolvimento e, consequentemente, não terem atingido a estabilização produtiva, uma vez que os anos de cultivo considerados nesta avaliação corresponderam ao $3^{\circ}, 4^{\circ}$ e $5^{\circ}$ anos de idade do pomar.

Considerando o desempenho das progênies ao longo das safras em estudo, as maiores médias de alturas de planta foram constatadas nas progênies formadas a partir dos cruzamentos entre CCP 76 e Embrapa 51 (3,05 m), BRS 226 e Embrapa 51 (2,86 m), CCP 76 e HAC 222/4 (2,76 m), e entre CCP 76 e BRS Bahia 12 (2,74 m), conforme representado na Figura 2. As progênies que revelaram menor média de altura de planta foram originadas dos cruzamentos entre CCP 76 e BRS 226 (2,43 m), e entre CCP 76 e A. microcarpum $(2,54 \mathrm{~m})$; contudo, tal desempenho não diferiu estatisticamente do apresentado pelas progênies originadas dos cruzamentos CCP 76 x BRS Bahia 12 e CCP 76 x HAC 222/4. Em relação ao diâmetro médio da copa, as maiores envergaduras de planta foram apresentadas pelas progênies originadas dos cruzamentos entre BRS 226 e Embrapa 51 (média igual a 5,28 m), CCP 76 e Embrapa 51 (4,96 m), e entre CCP 76 e HAC 222/4 (4,78 m). Os cruzamentos que originaram plantas com menores envergaduras de copa foram CCP 76 x BRS Bahia 12 (4,22 m), CCP 76 x BRS 226 (4,48 m) e CCP 76 x HAC 276/1 (4,36 $\mathrm{m})$, não diferindo estatisticamente do desempenho apresentado pela progênie obtida do cruzamento entre CCP 76 e HAC 222/4.

O porte da planta constitui um dos caracteres 
de maior importância no melhoramento genético do cajueiro (TAVARES et al., 2011), sendo priorizada a seleção de plantas com estatura reduzida, pela maior facilidade nas práticas de manejo do pomar, como poda, controle de pragas e doenças, e, principalmente, na colheita de frutos. Adicionalmente, tem-se buscado a seleção de plantas com conformação de copa que permitam maior adensamento de plantas e, ao mesmo tempo, possibilite atingir elevadas produtividades (PAIVA et al., 2005). Neste sentido, é possível verificar que existe variabilidade entre os híbridos em avaliação em relação a estes caracteres, os quais podem constituir possíveis genitores em blocos de cruzamentos, ou mesmo vir a se tornar fontes de futuros clones comerciais desde que apresentem desempenho satisfatório nos demais caracteres agronômicos de interesse.

A massa de castanha representa um dos caracteres mais trabalhados no melhoramento genético do cajueiro, uma vez que corresponde ao alvo da seleção indireta, visando à obtenção de ganhos genéticos sobre a massa da amêndoa, produto de grande importância econômica. No geral, amêndoas provenientes de castanhas com massa superior a 12 gramas atingem remunerações mais elevadas (PAIVA et al., 2007). Nessa avaliação, os cruzamentos que evidenciaram progênies com massas médias de castanha superiores foram BRS 226 x Embrapa 51 (9,78 g), e CCP 76 x BRS Bahia 12 (9,14 g), enquanto o cruzamento entre CCP 76 e $A$. microcarpum gerou a progênie com menor desempenho nesse caráter $(6,65$ g). Genótipos de $A$. microcarpum são utilizados em blocos de cruzamentos com genótipos-elite de $A$. occidentale visando, principalmente, à doação de alelos que contribuam para a melhoria da qualidade do pedúnculo, como redução da adstringência, acidez e melhoria da textura (CRISÓSTOMO et al., 2002). Contudo, uma vez que plantas de A. microcarpum apresentam, corriqueiramente, castanhas e pseudofrutos caracteristicamente pequenos, alelos que conferem tal característica também são transmitidos para suas progênies quando esses são utilizados como genitores em cruzamentos controlados.

Em relação ao número de castanhas por planta, é possível destacar o cruzamento CCP 76 $\mathrm{x}$ Embrapa 51, cuja progênie formada evidenciou o maior desempenho médio absoluto nesse caráter, com média igual a 379,52 castanhas por planta, não diferindo estatisticamente das progênies obtidas dos cruzamentos CCP 76 x HAC 276/1 (324,02 unidades), BRS 226 x Embrapa 51 (316,54 unidades), CCP 76 x A. microcarpum (284,19 unidades), e CCP 76 x BRS 226 (254,92 unidades). Enquanto isso, desempenhos inferiores nesse caráter foram apresentados pelas progênies originadas dos cruzamentos CCP $76 \mathrm{x}$ BRS Bahia 12 (192,23 unidades) e CCP 76 x HAC 222/4 (209,56 unidades). No entanto, não diferiram estatisticamente das médias apresentadas pelas progênies dos cruzamentos CCP 76 x HAC 276/1, BRS 226 x Embrapa 51, CCP 76 x A. microcarpum e CCP 76 x BRS 226.

As progênies cujo clone Embrapa 51 constitui um dos genitores apresentaram as maiores produtividades médias absolutas entre os híbridos testados, sendo constatadas as médias de 655,06 e $649,72 \mathrm{~kg}$ de castanha por hectare para os cruzamentos CCP 76 x Embrapa 51 e BRS 226 $\mathrm{x}$ Embrapa 51, respectivamente. Contudo, esses desempenhos não diferiram estatisticamente em relação às produtividades médias evidenciadas pelas progênies dos cruzamentos CCP 76 x HAC 276/1 $\left(582,19 \mathrm{~kg} \mathrm{ha}^{-1}\right)$ e CCP 76 x BRS $226\left(423,95 \mathrm{~kg} \mathrm{ha}^{-1}\right)$. Os híbridos formados dos cruzamentos CCP $76 \times \mathrm{A}$. microcarpum $\left(382,68 \mathrm{~kg} \mathrm{ha}^{-1}\right)$, CCP 76 x HAC 222/4 $\left(391,61 \mathrm{~kg} \mathrm{ha}^{-1}\right)$ e CCP 76 x BRS Bahia $12(403,59$ $\mathrm{kg} \mathrm{ha}^{-1}$ ) apresentaram as menores produtividades absolutas; entretanto, não diferiram estatisticamente em relação às progênies de CCP 76 x HAC 276/ e CCP 76 x BRS 226. Esses valores já ultrapassam de forma expressiva a média de produção no Brasil, que na safra de 2012 foi de $106,5 \mathrm{~kg} \mathrm{ha}^{-1}$ (FAOSTAT, 2014), ressaltando-se a existência de indivíduos superiores constituindo cada progênie, candidatos promissores para a seleção.

Os coeficientes de correlação fenotípica $\left(\mathrm{r}_{\mathrm{p}}\right)$, genotípica $\left(r_{G}\right)$ e ambiental $\left(r_{E}\right)$ entre os caracteres avaliados, considerando o desempenho conjunto dos híbridos ao longo das safras de 2010, 2011 e 2012, estão apresentados na Tabela 2. Nessa avaliação, foi possível detectar a existência de diferenças na ocorrência, no sentido e na magnitude das correlações entre os caracteres morfológicos e produtivos considerados. As magnitudes das correlações genéticas foram ligeiramente superiores às correlações fenotípicas em seis das dez relações consideradas. Esse comportamento pode ser atribuído aos efeitos modificadores do ambiente sobre as associações entre os caracteres, refletindo na redução de sua expressão fenotípica diante das influências do ambiente.

Os caracteres com elevada magnitude de correlação, tanto fenotípica quanto genotípica, podem ser considerados nas estratégias de seleção; contudo, as correlações genéticas envolvem uma associação de natureza herdável e, por isso, podem contribuir de forma mais efetiva na orientação das estratégias de melhoramento (GONÇALVES 
et al., 2008). Segundo Guerra e Livera (1999), as correlações podem ser classificadas segundo sua intensidade como muito forte $(\mathrm{r} \pm 0,91 \mathrm{a} \pm 1,00)$, forte $(\mathrm{r} \pm 0,71 \mathrm{a} \pm 0,90)$, média $(\mathrm{r} \pm 0,51 \mathrm{a} \pm 0,70)$ e fraca $(\mathrm{r}$ $\pm 0,31 \mathrm{a} \pm 0,50)$. Nesta avaliação, foram constatadas correlações positivas de mediana intensidade entre a altura de planta e o diâmetro de copa $\left(\mathrm{r}_{\mathrm{G}}=0,51\right.$; $\left.r_{p}=0,56\right)$, e desses caracteres com o número de castanhas por planta $\left(r_{G}=0,56 ; r_{p}=-0,54 ; e\left(r_{G}=0,45\right.\right.$; e $r_{p}=0,47$, respectivamente). Logo, o maior número de castanhas produzidas esteve relacionado ao maior tamanho de planta (estatura e diâmetro), e as maiores estaturas de plantas associaram-se positivamente aos maiores diâmetros de copa, concordando com outros autores (BARROS et al., 2000; TAVARES et al., 2011). Foi possível observar relações positivas de intensidade forte e mediana da produtividade de castanha com a altura de planta $\left(\mathrm{r}_{\mathrm{G}}=0,80 ; \mathrm{r}_{\mathrm{p}}=0,75\right) \mathrm{e}$ com o diâmetro da copa $\left(\left(\mathrm{r}_{\mathrm{G}}=0,68 ; \mathrm{r}_{\mathrm{P}}=0,66\right)\right.$, como verificado também por Barros et al. (2000). A massa média da castanha apresentou correlação positiva com o desempenho dos caracteres morfológicos (altura de planta: $\mathrm{r}_{\mathrm{G}}=0,60 ; \mathrm{r}_{\mathrm{p}}=0,54$; diâmetro de copa: $\left.r_{G}=0,54 ; r_{p}=0,48\right)$. Desta forma, para as condições consideradas nesta avaliação, o maior potencial produtivo e a maior qualidade de castanha estiveram associados ao maior tamanho de planta (altura e diâmetro).

A produtividade de castanha mostrou forte relação positiva com o número de castanhas por planta $\left(r_{\mathrm{G}}=0,84 ; r_{\mathrm{p}}=0,86\right)$ e de magnitude média com a massa média de castanha $\left(\mathrm{r}_{\mathrm{G}}=0,55 ; \mathrm{r}_{\mathrm{p}}=0,48\right)$. Logo, é possível sugerir que ambos os caracteres representam importantes componentes da produtividade de castanhas evidenciada pelos híbridos, contudo com destaque maior ao número de castanhas por planta. Não foram constatadas relações significativas entre a massa média e o número de castanhas por planta $\left(\mathrm{r}_{\mathrm{G}}=\right.$ 0,$\left.03 ; r_{p}=-0,04\right)$, sugerindo a possibilidade de obtenção de ganhos genéticos em ambos os caracteres com o processo de seleção sobre o conjunto de indivíduos considerados.

Foi observada considerável influência do ambiente na manifestação dos caracteres, evidenciada pelas correlações ambientais significativas, positivas e negativas. Foi constatada correlação ambiental negativa entre o número total e a massa média da castanha, indicando que o ambiente favoreceu um caráter em detrimento do outro. Enquanto isso, todas as demais correlações ambientais significativas foram positivas; logo, ambos os caracteres foram prejudicados ou beneficiados pelas mesmas variações de ambiente.

A redução do porte da planta do cajueiro tem sido um dos focos do melhoramento do cajueiro, a fim de desenvolver plantas altamente produtivas e de menor volume, permitindo assim o adensamento entre plantas, vinculado a maior facilidade de manejo do pomar. Contudo, os resultados observados nessa avaliação sugerem que a seleção preconizada, visando ao reduzido porte de planta, característico de plantas de cajueiro-anão, pode ser acompanhada pela diminuição na produtividade de castanha, em função da restrição do potencial produtivo da planta no que diz respeito à estrutura morfológica e à capacidade fotossintética. Logo, para a maior eficiência do desenvolvimento de genótipos superiores, é necessário realizar um processo de seleção que permita a eleição de genótipos produtivos, que evidenciem massa média de castanha condizente às exigências do mercado consumidor, associado ao porte de planta equilibrado, capaz de garantir a produtividade constante e em níveis economicamente satisfatórios, associados à maior facilidade de manejo do pomar.

Com base nos resultados obtidos nessa avaliação, podem ser realizadas seleções de plantas individuais dentro das progênies provenientes dos cruzamentos BRS 226 x Embrapa 51, CCP 76 x Embrapa 51, CCP 76 x HAC 276/1 e CCP $76 \times$ BRS 226, que se destacaram pelo maior rendimento de castanhas, priorizando as plantas que evidenciaram maior massa média de castanha e menor estrutura vegetativa (altura de planta e diâmetro de copa). Plantas superiores quanto a esses caracteres também poderão ser selecionadas dentro das demais progênies avaliadas. Ao mesmo tempo, na progênie formada pelo cruzamento CCP 76 x $A$. microcarpum, poderão ser selecionados os híbridos com elevado número de frutos associado à adequada qualidade organoléptica do pedúnculo (avaliações em andamento), próprios para o consumo do fruto in natura. As plantas selecionadas constituirão fonte de material de propagação para a implantação de ensaios de competição de clones e cuja recombinação originará sementes a serem utilizadas na formação de novas progênies que alimentarão os subsequentes ciclos de seleção recorrente. Além disso, os híbridos selecionados poderão ser também utilizados como genitores em futuros blocos de cruzamentos direcionados, buscando atender às demandas do programa de melhoramento. A tomada de decisão quanto à seleção das plantas deverá considerar, conjuntamente, o desempenho dessas em relação à ocorrência das principais doenças que atingem a cultura do cajueiro na região litorânea do Estado do Ceará, que são o oídio (Oidium anacardii), a antracnose (Colletotrichum gloeosporioides) e o mofo-preto (Pilgeriella anacardii), avaliações essas que são corriqueiramente realizadas pela equipe de melhoramento. 


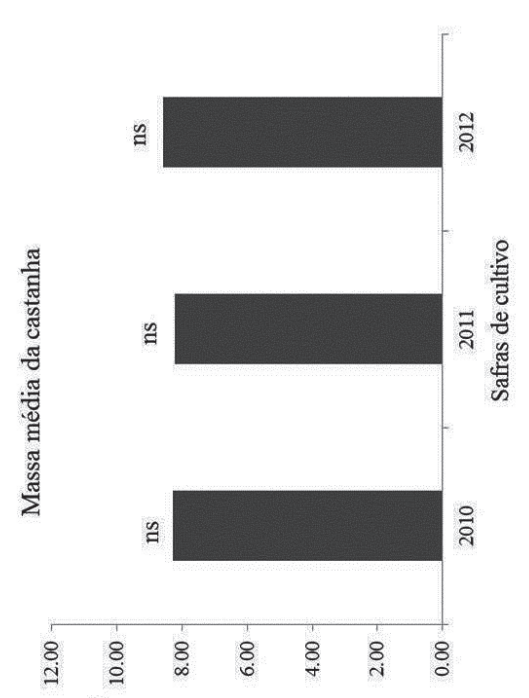

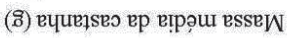

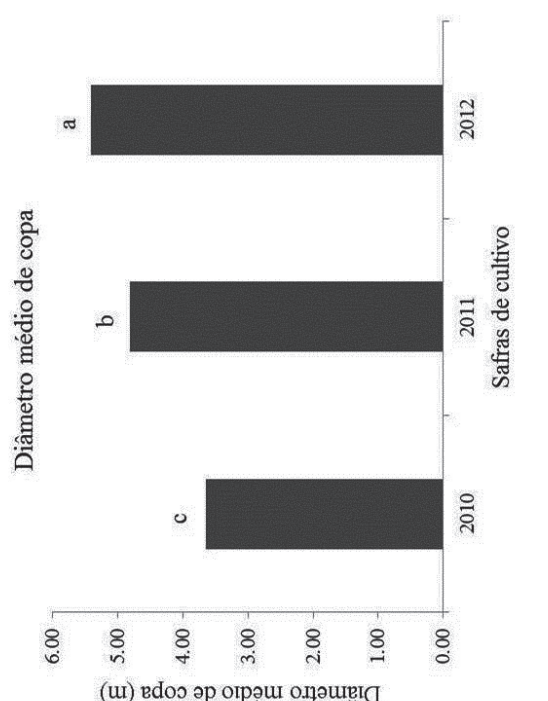

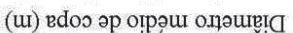
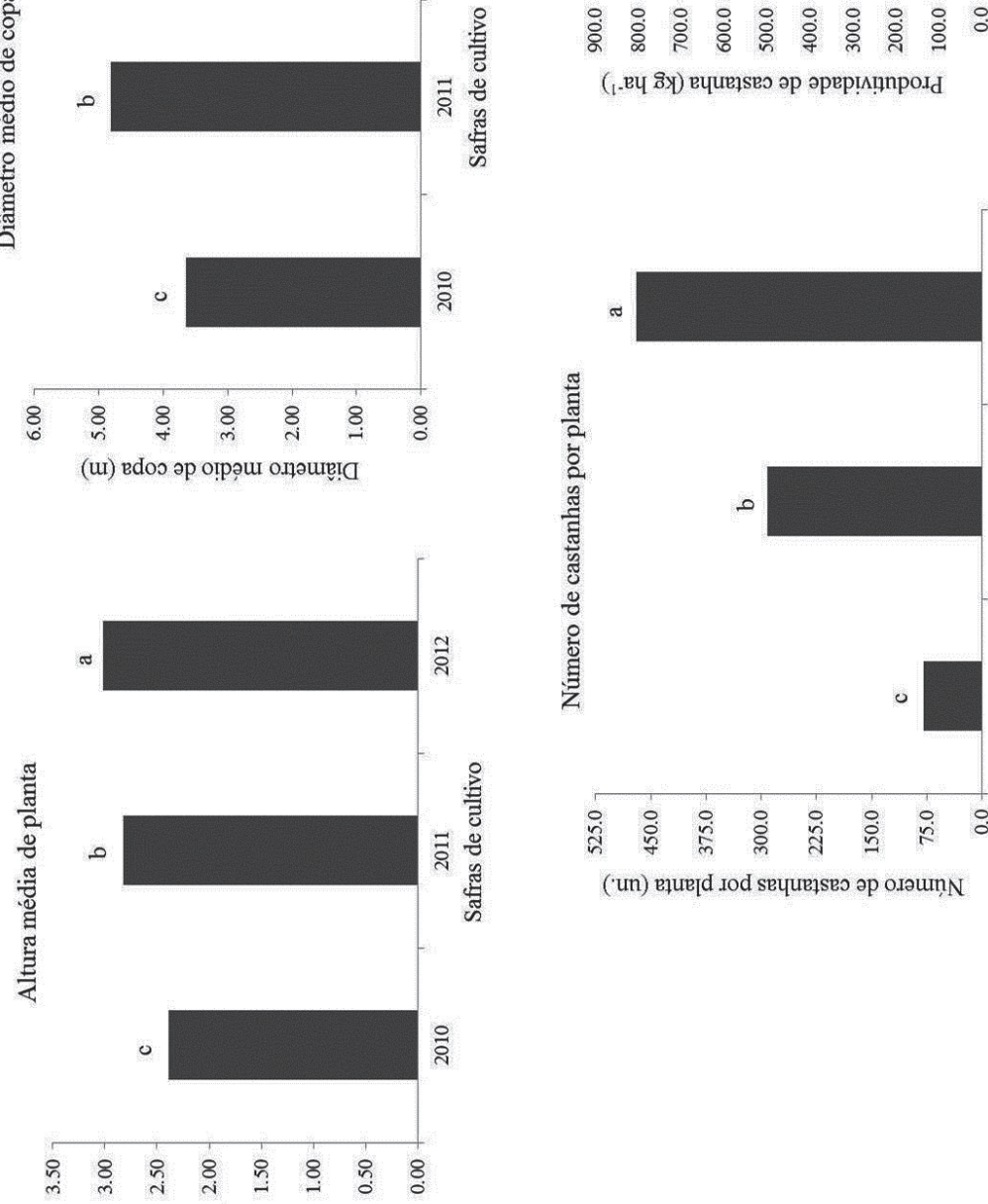

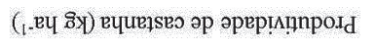

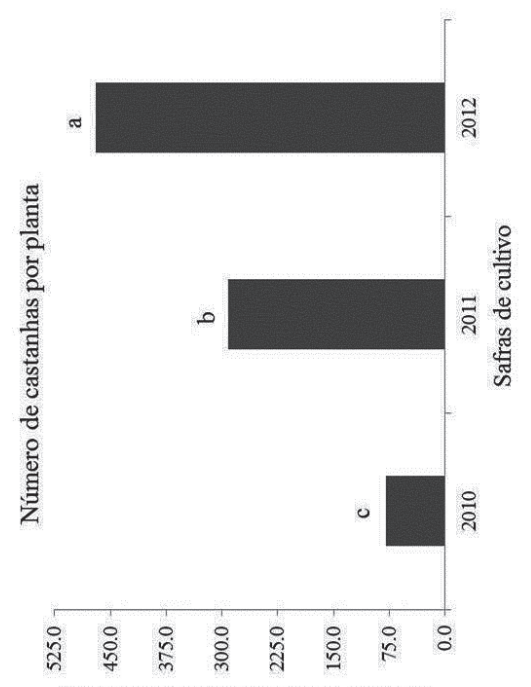

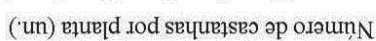

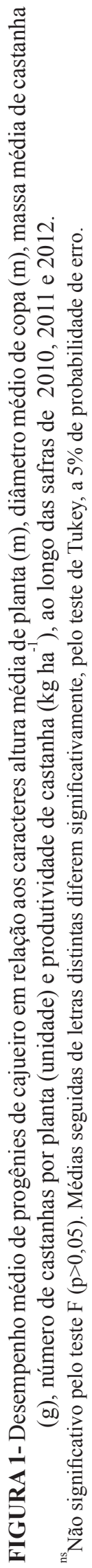

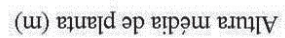



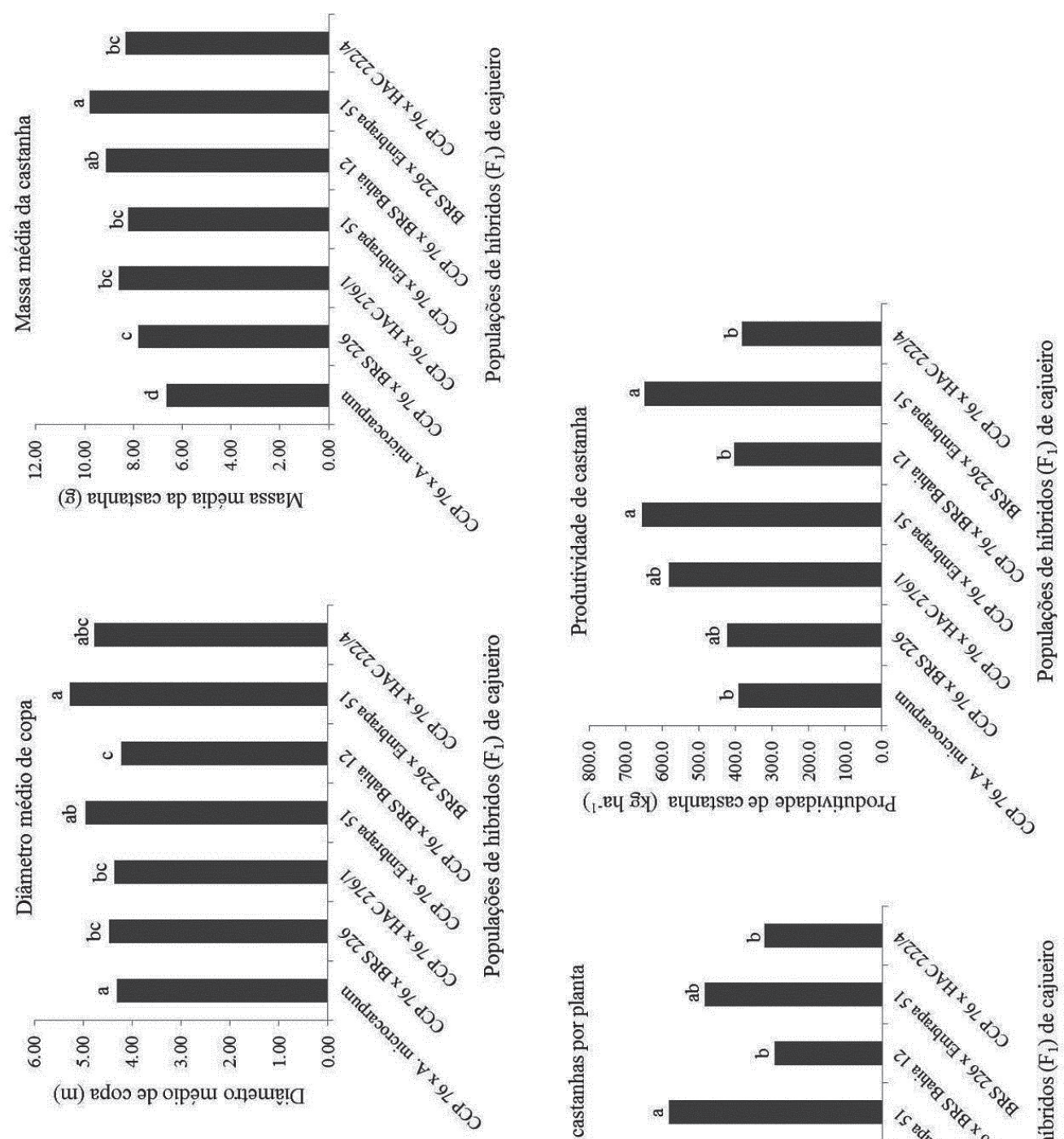

שี

ఏ્છ

ํํㅇ

正

응

ฮ

䒿 守

胥

ช.

ఏ킹

플 을

궁

응 00

큭

壳

焉焉

웜

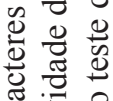

헝일

)ำ

胥

苑

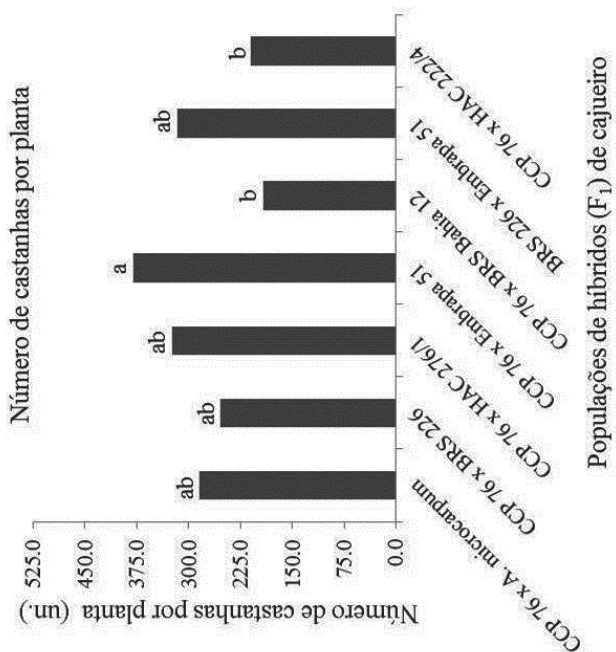

.

है

章

논

후웜

ำ

过

용

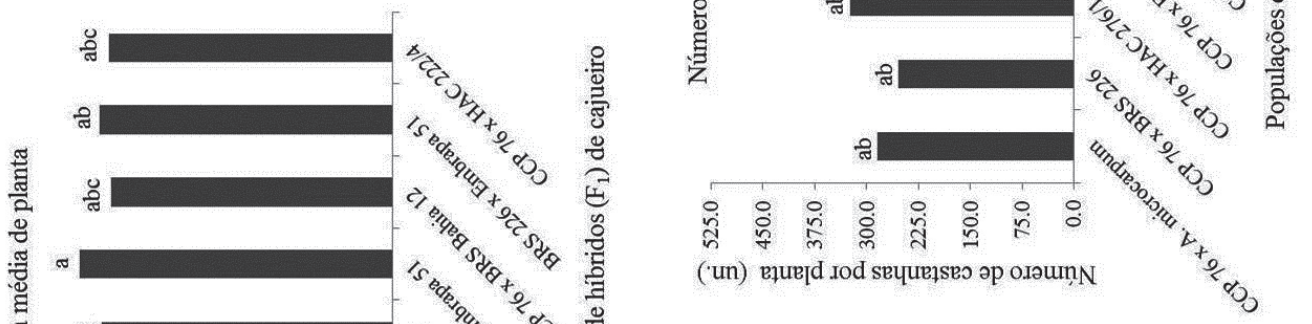

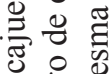

\%

嗐

焉酸:

행

\%

웡

ज्ञ

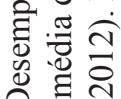

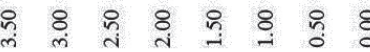

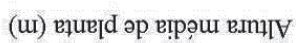

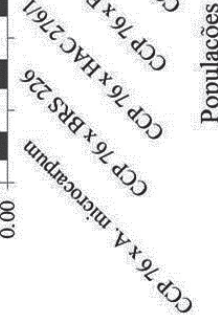

$\frac{1}{2}$ 
TABELA 1- Resumo da análise de variância em relação aos caracteres altura de planta (m), diâmetro de copa $(\mathrm{m})$, produtividade de castanha $\left(\mathrm{kg} \mathrm{ha}^{-1}\right)$, número de castanhas por planta (unidade) e massa média de castanha (g), mensurados em progênies de cajueiro cultivadas nas safras de 2010, 2011 e 2012, no Município de Pacajus, Ceará.

\begin{tabular}{|c|c|c|c|c|c|c|}
\hline \multirow[b]{2}{*}{ Fonte de Variação } & \multirow[b]{2}{*}{$\mathrm{GL}$} & \multicolumn{5}{|c|}{ Quadrado médio } \\
\hline & & $\begin{array}{c}\text { Altura } \\
\text { de planta }\end{array}$ & $\begin{array}{l}\text { Diâmetro } \\
\text { de copa }\end{array}$ & $\begin{array}{l}\text { Produtividade } \\
\text { de castanha }\end{array}$ & $\begin{array}{l}\text { Número de castanhas } \\
\text { por planta }\end{array}$ & $\begin{array}{r}\text { Massa média } \\
\text { de castanha }\end{array}$ \\
\hline & & ---------- & m ------------ & ---- $\mathrm{kg} \mathrm{ha}^{-1}$---- & ---- unidade ---- & ---- g ---- \\
\hline Bloco & 3 & 0,145 & 0,992 & 148825,526 & 51581,169 & 3,131 \\
\hline Progênie (P) & 6 & $0,508^{* *}$ & $1,837^{* *}$ & $187577,144^{* *}$ & $52978,512^{* *}$ & $11,915^{* *}$ \\
\hline Ano de cultivo (A) & 2 & $2,886^{* *}$ & $22,582^{* *}$ & $2381605,460^{* *}$ & $1071113,639^{* *}$ & $0,987^{\mathrm{ns}}$ \\
\hline $\mathrm{P} \times \mathrm{A}$ & 12 & $0,030^{\mathrm{ns}}$ & $0,160^{\mathrm{ns}}$ & $48180,54094^{\mathrm{ns}}$ & $13459,374^{\mathrm{ns}}$ & $0,280^{\mathrm{ns}}$ \\
\hline Resíduo & 18 & 0,090 & 0,268 & 36026,731 & 16009,866 & 0,677 \\
\hline Média & & 2,74 & 4,62 & 498,40 & 280,14 & 8,37 \\
\hline $\mathrm{CV}(\%)$ & & 10,92 & 11,18 & 38,08 & 45,17 & 9,83 \\
\hline
\end{tabular}

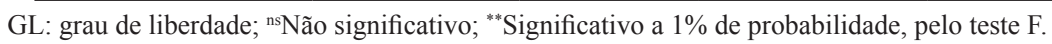

TABELA 2- Coeficientes de correlação fenotípica $\left(r_{p}\right)$, genotípica $\left(r_{G}\right)$ e ambiental $\left(r_{E}\right)$ entre caracteres de interesse agronômico mensurados a partir do desempenho de progênies de cajueiro avaliadas nas safras de 2010, 2011e 2012, no Município de Pacajus, Ceará.

\begin{tabular}{|c|c|c|c|c|}
\hline Caracteres & $\begin{array}{l}\text { Diâmetro de copa } \\
\qquad(\mathrm{m})\end{array}$ & $\begin{array}{l}\text { Número total } \\
\text { de castanhas } \\
\text { (unidade) }\end{array}$ & $\begin{array}{c}\text { Massa } \\
\text { média de } \\
\text { castanha }(\mathrm{g})\end{array}$ & $\begin{array}{l}\text { Produtividade } \\
\text { de castanha } \\
\left(\mathrm{kg} \mathrm{ha}^{-1}\right)\end{array}$ \\
\hline & \multicolumn{4}{|c|}{ Correlação fenotípica $\left(r_{p}\right)$} \\
\hline Altura de planta (m) & $0,56^{* *}$ & $0,54^{* *}$ & $0,54^{* *}$ & $0,75^{* *}$ \\
\hline Diâmetro de copa (m) & -- & $0,47^{* *}$ & $0,48^{* *}$ & $0,66^{* *}$ \\
\hline Número total de castanhas (un.) & & -- & $-0,04$ & $0,86^{* *}$ \\
\hline \multirow[t]{2}{*}{ Massa média de castanha $(\mathrm{g})$} & & & -- & $0,48^{* *}$ \\
\hline & \multicolumn{4}{|c|}{ Correlação genotípica $\left(r_{G}\right)$} \\
\hline Altura de planta (m) & $0,51^{* *}$ & $0,56^{* *}$ & $0,60^{* *}$ & $0,80^{* *}$ \\
\hline Diâmetro de copa (m) & -- & $0,45^{* *}$ & $0,54^{* *}$ & $0,68^{* *}$ \\
\hline Número total de castanhas (un.) & & -- & $-0,03^{\mathrm{ns}}$ & $0,84^{* *}$ \\
\hline \multirow[t]{2}{*}{ Massa média de castanha $(\mathrm{g})$} & & & -- & $0,55^{* *}$ \\
\hline & \multicolumn{4}{|c|}{ Correlação ambiental $\left(r_{E}\right)$} \\
\hline Altura de planta (m) & $0,81^{* *}$ & $0,48^{* *}$ & $0,12^{*}$ & $0,51^{* *}$ \\
\hline Diâmetro de copa (m) & -- & $0,56^{* *}$ & $0,04^{\mathrm{ns}}$ & $0,59^{* *}$ \\
\hline Número total de castanhas (un.) & & -- & $-0,14^{*}$ & $0,92^{* *}$ \\
\hline Massa média de castanha $(\mathrm{g})$ & & & -- & $0,02^{\text {ns }}$ \\
\hline
\end{tabular}

*Significativo a $5 \%$ de probabilidade; $* *$ Significativo a $1 \%$ de probabilidade. 


\section{CONCLUSÕES}

Os cruzamentos BRS 226 x Embrapa 51; CCP 76 x Embrapa 51; CCP 76 x HAC 276/1, e CCP 76 x BRS 226 mostram-se promissores na geração de genótipos superiores para caracteres de interesse agronômico. Ressalta-se a necessidade de realizar a seleção, buscando o equilíbrio em relação ao desempenho nos caracteres morfológicos e produtivos, para potencializar a possibilidade de obtenção de genótipos que evidenciem elevada produtividade de castanhas, com massa média satisfatória, associado ao porte de planta que facilite o manejo do pomar.

\section{REFERÊNCIAS}

BARROS, L.M.; CAVALCANTI, J.J.V.; PAIVA, J.R.; CRISÓSTOMO, J.R.; CORRÊA, M.P.F.; LIMA, A.C. Seleção de clones de cajueiro-anão para o plantio comercial no Estado do Ceará. Pesquisa Agropecuária Brasileira, Brasília, v.35, n.11, p.2197-2204, 2000.

CAVALCANTI, J.J.V.; PINTO, C.A.B.P.; CRISÓSTOMO, J.R.; FERREIRA, D.F. Análise dialélica para avaliação de híbridos interpopulacionais de cajueiro. Pesquisa Agropecuária Brasileira, Brasília, v.35, n.8, p.1567-1575, 2000.

CAVALCANTI, J.J.V.; RESENDE, M.D.V. Seleção precoce intensiva: uma nova estratégia para o programa de melhoramento genético do cajueiro. Revista Brasileira de Fruticultura, Jaboticabal, v.32, n.4, p.1279-1284, 2010.

CAVALCANTI, J.J.V.; RESENDE, M.D.V.; CRISÓSTOMO, J.R.; BARROS, L.M.; PAIVA, J.R. Genetic control of quantitative traits and hybrid breeding strategies for cashew improvement. Crop Breeding and Applied Biotechnology, Viçosa, MG, v.7, p.186-195, 2007.
CRISÓSTOMO, J.R.; CAVALCANTI, J.J.V.; BARROS, L.M.; ALVES, R.E.; FREITAS, J.G.; OLIVEIRA, J.N. Melhoramento do cajueiro-anãoprecoce: avaliação da qualidade do pedúnculo e a heterose dos seus híbridos. Revista Brasileira de Fruticultura, Jaboticabal, v.24, n.2, p.477-480, 2002.

FAOSTAT - Food and Agriculture Organization of The United National. Prodution/crops. Disponível em: http://faostat.fao.org/site/567/DesktopDefault. aspx?PageID=567\#ancor. Acesso em: 11 maio 2014.

GONÇALVES, G.M.; VIANA, A.P.; REIS, L.S.; BEZERRA NETO, F.V.; AMARAL JÚNIOR, A.T.; REIS, L.S. Correlações fenotípicas e genéticoaditivas em maracujá-amarelo pelo delineamento I. Revista Ciência e Agrotecnologia, Lavras, v.32, n.5, p.1413-1418, 2008.

GUERRA, N.B.; LIVERA A.V.S. Correlação entre o perfil sensorial e determinações físicas e químicas do abacaxi cv. Pérola. Revista Brasileira de Fruticultura, Jaboticabal, v. 21, n.1, p.32-35, 1999.

IBGE - Instituto Brasileiro de Geografia e Estatística. Pesquisa mensal de previsão e acompanhamento das safras agrícolas no ano civil. Levantamento Sistemático da Produção Agrícola, Rio de Janeiro, v.25, n.8, p.1-88, 2012.

OLIVEIRA, V.H.; COSTA, V.S.O. Manual de produção integrada de caju. Fortaleza: Embrapa Agroindústria Tropical, 2005. 355 p.

PAIVA, J.R.; BARROS, L.M.; CAVALCANTI, J.J.V.; LIMA, A.C.; CORRÊA, M.C.M.; MELO, D.S. Seleção de clones de cajueiro comum para plantio comercial na região Nordeste. Revista Ciência Agronômica, Fortaleza, v.36, n.3, p.327-332, 2005.

PAIVA, J.R.; CAVALCANTI, J.J.V.; BARROS, L.M.; CORRÊA, M.C.M.; MAIA, M.C.C.; COSTA FILHO, A.B. Seleção de clones de cajueiro comum pelo método em tandem e índice de classificação. Revista Ciência e Agrotecnologia, Lavras, v.31, n.3, p.765-772, 2007. 
TARSITANO, M.A.A.; ARAÚJO, D.C.;COSTA, T.V.; COSTA, S.M.A.L.; SANTANA, A.L. Custos de comercialização e mercado do caju in natura na regional de Jales, Estado de São Paulo. Informações Econômicas, São Paulo, v.40, n.4, p.12-20, 2010.
TAVARES, T.M.; SCIBENEICHLER, S.C.; CAVALCANTI, J.J.V.; AFÉRRI, F.S.; SOUZA, C. M.; NUNES, T.V. Desempenho fenológico de progênies de meios-irmãos de cajueiro-anão-precoce na região central do Tocantins, no primeiro ano de plantio. Revista Brasileira de Ciências Agrárias, Recife, v.6 n.1, p.98-104, 2011. 